\title{
Penerapan Metode Analisis Beban Kerja untuk Meningkatkan Produktivitas di Bagian Case Assy Up di PT. Yamaha Indonesia
}

\author{
Hatta Arifin \\ Program Studi Teknik Industri, Fakultas Teknologi Industri, Universitas Islam Indonesia \\ Jl. Kaliurang KM. 14,5 Sleman Yogyakarta, 55584, Indonesia \\ E-mail : hatta.arifin@gmail.com
}

\begin{abstract}
ABSTRAK
Dunia perekonomian yang semakin kompetitif di bidang perindustrian dan manufaktur membuat banyak perusahaan tidak mampu bersaing dengan kompetitor di bidangnya. Pada bagian Case Assy UP di PT.Yamaha Indonesia terdapat permasalahan operator yang masih banyak waktu luang dan pembagian uraian pekerjaan yang belum seimbang sehingga produktivitas yang dihasilkan tidak maksimal. Pada penelitian ini, data yang diambil dari lembar pengamatan yang berisikan tentang aktivitas-aktivitas kerja operator yaitu waktu penyelesaian pekerjaan tersebut yang akan disesuaikan dengan uraian pekerjaan pada tiap-tiap posisi. Analisis beban kerja memberikan pengukuran yang tepat untuk menentukan berapa jumlah operator yang dibutuhkan dan menentukan beban kerja yang tepat untuk setiap operator. Sehingga menentukan hasil akhir dari pekerjaan yaitu produktivitas. Dengan menggunakan metode analisis beban kerja hasil yang diperoleh adalah rata-rata hasil produktivitas meningkat sebesar 33\% dibandingkan dengan rata-rata produktivitas awal. Beban kerja operator menjadi lebih seimbang karena beban kerja awal tertinggi 92,25\% dan beban kerja terendah sebesar 67,93\%, sedangkan setelah perbaikan beban kerja tertinggi 99,97\% dan beban kerja terendah sebesar 96,28\%. Jumlah operator adalah 8 orang setelah dilakukan penelitian maka diperoleh jumlah operator ideal adalah 6 orang.
\end{abstract}

Kata Kunci : Analisis Beban Kerja, Uraian Pekerjaan, Operator, Produktivitas.

\section{Application of Work Load Analysis Method to Improve Productivity in the Case Assy Up at PT. Yamaha Indonesia}

\begin{abstract}
Competitive world economy in industry and manufacturing has made many companies unable to compete with competitors in their fields. In the Case Assy UP section at PT. Yamaha Indonesia there are operator problems that still have a lot of free time and not balanced job description generate nonoptimal productivity. In this case, the data taken from the observation sheet containing the operator's work activities, namely the time of completion of the work, will be adjusted to the job description of the job in each position. Workload analysis provides precise measurements to determine how many operators are needed and determine the right workload for each operator. So that determines the final result of the work that is productivity. By using the workload analysis method, the results obtained are the average productivity results increased by $33 \%$ compared to the average initial productivity. Operator workload became more balanced because the highest initial workload was $92.25 \%$ and the lowest workload was $67.93 \%$, while after repairing the highest workload was $99.97 \%$ and the lowest workload was $96.28 \%$. The number of operators is 8 people after the research, the ideal number of operators is 6 people.
\end{abstract}

Keywords : Workload Analysis, Job Description, Operator, Productivity 


\section{Pendahuluan}

Sebuah persaingan dalam bidang industri tentu bukan hal yang baru namun tetap menjadi focus penting demi kelangsungan sebuah bisnis atau perusahaan tetap berjalan. Setiap perusahaan tentu terus berusahan untuk mencari langkah yang lebih baik dan lebih baik seterusnya, serta selalu berusaha mengantisipasi ancaman yang mampu mengurangi segala nilai aspek perusahaan. Pedoman awal adalah nilai UMP (Upah Minimum Profinsi) yang setiap waktu meningkat maka mau tak mau perusahaan harus juga meningkat dalam hal profit atau keuntungan untuk memenuhi UMP.

Produktivitas perusahaan merupakan hal yang penting bagi semua perusahaan. Kenaikan dan penurunan produktivitas perusahaan memiliki korelasi positif dengan besaran profit yang diperoleh perusahaan(Hidayat \& Partiwi, 2018). Bloche, (2007:307) menjelaskan bahwa ukuran produktivitas bisa dilihat dengan dua cara yaitu produktivitas operasional dan produktivitas finansial. Produktivitas opersional adalah rasio unit output terhadap unit input. Baik pembilang maupun penyebutnya merupakan ukuran fisik (dalam unit). Produktivitas finansial juga merupakan rasio output terhadap input, tetapi angka pembiang atau penyebutnya dalam satuan mata uang (rupiah). PT Yamaha Indonesia (YI) yang berdiri sejak tahun 1970, merupakan salah satu perusahaan yang bergerak dalam bidang pembuatan dan perakitan alat musik piano. Sebagai salah satu cabang perusahaan Yamaha Coorporation Japan, tentu selalu dituntut untuk berusaha meningkatkan produktifitas. Dalam kasus beberapa proses pembelajaran paralel yang menerapkan model penyeimbangan untuk masing-masing proses pembelajaran dan menggabungkan hasil yang diperoleh, dimungkinkan untuk memberikan \ kontrol beban yang kompleks selama proses pembelajaran(Balina et al., 2015), dari dasar pemikiran ini poin pentingnya adalah penyeimbangan dalam hal ini penyeimbangan proses semua elemen produksi untuk dapat mengontrol produksi keseluruhan.

Beban kerja karyawan dan kompleksitas tugas adalah fungsi dari organisasi struktur nasional. Bahkan di dalam organisasi yang sama, persyaratan tugas karyawan berbedabeda karena karyawan dengan peringkat yang sama mungkin ditugaskan secara tidak setara

Tetapi bahkan dalam departemen yang sama, tidak ada jaminan bahwa beban kerja karyawan akan seimbang(Inegbedion et al., 2020). analisa beban kerja (workload analysis) adalah proses untuk menetapkan jumlah jam kerja orang yang digunakan atau dibutuhkan untuk menyelesaikan suatu pekerjaan dalam waktu tertentu, atau dengan kata lain analisis beban kerja bertujuan untuk menentukan berapa jumlah personalia dan berapa jumlah tanggung jawab atau beban kerja yang tepat dilimpahkan kepada seorang petugas. Analisis beban kerja adalah suatu teknik manajemen yang dilakukan secara sistematis untuk memperoleh informasi mengenai tingkat efektifitas dan efisiensi kerja oraganisasi(Adawiyah, 2013).

Dalam menjalankan produksi dengan baik dibutuhkan rangkaian sistem produksi yg baik. Sistem produksi ialah kumpulan dari subsistem yang saling berkaitan, dengan tujuan mentransformasi input produksi menjadi output produksi. Input produksi ini bisa berbentuk bahan baku, mesin,tenaga kerja, modal dan informasi (Rahmat Hermawan \& Banjarsari, 2019).

Untuk meningkatkan produktivitas dan efisiensi jalur produksi di industri makanan kecil dan menengah. Berdasarkan data yang dikumpulkan melalui pengamatan, wawancara dan studi dokumen dan laporan produksi, penyeimbangan lini telah diidentifikasi sebagai masalah yang mempengaruhi efisiensi jalur produksi(Mishan \& Tap, 2015)

Workload analysis memberikan pengukuran yang tepat untuk menentukan berapa jumlah operator yang dibutuhkan dan menentukan beban kerja yang tepat untuk setiap operator. 
Sehingga menentukan hasil akhir dari pekerjaan yaitu produktivitas. Pengertian dari perencanaan sumber daya manusia adalah merencanakan tenaga kerja agar sesuai dengan kebutuhan perusahaan secara fektif dan efisien dalam membantu terwujudnya tujuan (Ridha et al., 2013). Apabila petugas(pekerja) tempat pendaftaran pasien tidak seimbang dengan beban kerja, jumlah pasien yang berkunjung dan jumlah jam kerja maka produktivitas petugas (pekerja) pendaftaran pasien(customers) menurun, dengan demikian dalam menjaga produktivitas petugas(pekerja) suatu rumah sakit jumlah tenaga kerja harus direncanakan dengan sebaik-sebaiknya (Lestari, 2014).

Work analisys dilakukan untuk mempelajari tentang beban kerja dan kemungkinan hambatan yang muncul selama bekerja, dan berfungsi sebagai dasar dari semua kegiatan manajemen sumber daya manusia dalam organisasi(Ariani et al., 2019). Dari uraian diatas, maka penelitian dilakukan di PT.Yamaha Indonesia dengan judul Penerapan Metode Workload Analysis Untuk Meningkatkan Produktivitas Di Bagian Case Assy Up Di PT.Yamaha Indonesia.

\section{Metodologi}

Metode penelitian dilakukan dengan menggunakan metode wawancara awal pada ketua kelompok bagian Case Assy UP PT. Yamaha Indonesia, dan juga menggunakan data historis hasil produksi actual Case Assy Up selama 7 bulan dari ketua kelompok. Untuk melakukan analisis beban kerja dilakukan dengan metode time study dengan menghitung waktu yang dibutuhkan seorang tenaga kerja untuk menyelesaikan setiap pekerjaan sesuai dengan job description (Ridha et al., 2013). Menurut (Rizky Ramadhan et al., 2014) sebuah organisasi terdiri dari posisi-posisi yang harus dibuatkan sesunan stafnya. Agar dapat diperoleh pegawai yang berkualitas sebagaimana yang diharapkan maka cara terbaik yang harus dilakukan oleh pimpinan suatu organisasi adalah melakukan kegiatan analisis pekerjaan atau analisis jabatan, sehingga dengan demikian dapat terlihat jenis dan kompetensi pegawai yang diperlukan untuk suatu organisasi.

\subsection{Time Study}

Stopwatch time study adalah pengukuran waktu kerja secara langsung yang dilakukan dengan alat ukur waktu stopwatch. Penelitian dengan stopwatch time study memiliki beberapa tahapan yang harus dilakukan. Berikut ini adalah urutan langkah dalam stopwatch time study (Hidayat \& Partiwi, 2018):

1. Definisi pekerjaan yang akan diteliti untuk diukur waktunya dan beritahukan maksud dan tujuan pengukuran ini kepada pekerja yang dipilih untuk diamati dan supervisor yang ada.

2. Catat semua informasi yang berkaitan erat dengan penyelesaian pekerjaan seperti lay out, karakteristik /spesifikasi mesin atau peralatan kerja lain yang digunakan, dan lain-lain.

3. Bagi operasi kerja dalam elemen kerja sedetail-detailnya tapi masih dalam batasbatas kemudahan untuk pengukuran waktunya.

4. Amati, ukur dan catat waktu yang dibutuhkan oleh operator untuk menyelesaikan elemen-elemen kerja tersebut.

5. Tetapkan jumlah siklus kerja yang harus diukur dan dicatat. Teliti apakah jumlah siklus kerja yang dilaksanakan ini sudah memenuhi syarat atau tidak.

6. Tes pula keseragaman data yang diperoleh.

7. Tetapkan rate of performance dari operator saat melaksanakan aktivitas kerja yang diukur dan dicatat waktunya tersebut. Rate of performance ini ditetapkan untuk setiap elemen kerja yang ada dan hanya ditujukan untuk performance operator. Untuk elemen 
kerja yang secara penuh dilakukan oleh mesin maka performance dianggap normal $(100 \%)$.

\subsection{Analisis Beban Kerja}

Adalah suatu kondisi dari pekerjaan dengan uraian tugasnya yang harus diselesaikan pada batas waktu tertentu(Diana \& Harta, 2017). Tujuan analisis beban kerja adalah untuk memperoleh seberapa besar beban kerja relative dari seseorang tenaga kerja, suatu jabatan (pekerjaan), suatu unit kerja (seksi, bagian, divisi, cabang, wilayah), bahkan suatu organisasi/perusahaan secara keseluruhan (Kurnia,2008)(Ridha et al., 2013).

Tujuan dari analisis beban kerja adalah:

1. Untuk mengidentifikasi kebutuhan karyawan yang berkualitas atau kuantitas sekarang atau untuk masa depan

2. Sebagai tolok ukur kinerja karyawan secara terukur kerja baik waktu kerja maupun kerja 3. Meratakan beban kerja karyawan sesuai dengan minimum kebutuhan dan persyaratan pekerjaan

4. Sebagai panduan untuk meningkatkan keterampilan saat bekerja dan perencanaan referensi untuk pelatihan pengembangan untuk para karyawan(Hanjani \& Singgih, 2019).

Berdasarkan hasil pengukuran beban kerja pada PT. Sanjayatama Lestari dengan menggunakan metode Analisis Beban Kerja dapat di simpulkan bahwa rata-rata beban kerja karyawan pada bagian baguan Tabulator adalah 8650,866 jam / tahun dengan jumlah karyawan yang optimal adalah 4 orang. Pada bagian Adhoc rata-rata beban kerja sebelum dilakukan penelitian adalah 12.367,372 jam / tahun dengan jumlah karyawan yang optimal adalah 6 orang. Pada bagian HRD dan Trainer rata-rata beban kerja adalah 7452,393 jam / tahun dengan jumlah karyawan yang optimal adalah 4 orang. Pada bagian Umum rata-rata beban kerja adalah 15.938,237 jam / tahun dengan jumlah karyawan optimal adalah 8 orang (Anggraeni \& Prabowo, 2015).
Beban kerja dapat dihitung dengan rumus sebagai berikut :

$\mathrm{BK}=\frac{T W B}{T W K} \times 100 \%$

Dengan :

$\mathrm{BK}=$ beban kerja perhari $(\%)$

TWB = total waktu baku (menit)

TWK = total waktu kerja (menit)

Setelah dihitung beban kerja pada masingmasing operator, maka ditentukan hasil beban kerja menggunakan norma (normal/underload/overload). Berikut ini tabel norma yang ditentukan berdasarkan perhitungan beban kerja :

Tabel 1. Norma Beban Kerja

\begin{tabular}{ll}
\hline $\begin{array}{l}\text { Hasil perhitungan } \\
\text { beban kerja }\end{array}$ & Kategori \\
\hline$<100 \%$ & Underload \\
\hline $100 \%$ & Normal \\
\hline$>100 \%$ & Overload
\end{tabular}

Hitung waktu siklus rata - rata (average cycle time)

$$
\mathrm{Ws}_{\mathrm{s}}=\frac{\sum \mathrm{Xi}}{\mathrm{N}}
$$

Dengan :

$\mathrm{Xi}=$ waktu pengamatan

$\mathrm{N}=$ jumlah pengamatan

\subsection{Uji Kecukupan Data}

Uji kecukupan data dilakukan untuk mengetahui apakah data hasil pengamatan yang telah diambil sudah cukup mewakili populasinya, bila belum maka perlu diadakan pengamatan tambahan hingga cukup mewakili populasinya. Pada penelitian ini, digunakan tingkat keyakinan 95\%, tingkat ketelitian 5\%, dan menggunakan persamaan uji keseragaman data (Sutalaksana, dkk., 1979). 


\subsection{Uji Keseragaman Data}

Uji keseragaman data dilakukan untuk mengetahui apakah data-data yang diperoleh itu masuk kedalam batas kontrol atau bahkan diluar batas kontrol dengan menggunakan Peta Kendali $\bar{X}$ dan R. Adapun langkah-langkah dalam melakukan pengujian keseragaman data adalah sebagai berikut:

1. Menentukan jumlah hasil data keseluruhan yang kita peroleh dari pengumpulan data lapangan.. Mencari nilai $\bar{X}$ dengan rumus:

$$
\bar{X}=\frac{\sum X \bar{i}}{N}
$$

2. Menghitung standar deviasi dari waktu sebenarnya dengan rumus:

$$
\delta x=\sqrt{\frac{\sum(X i-\not x)^{2}}{N-1}}
$$

3. Mencari Batas Kontrol Atas (BKA) dan Batas Kontrol Bawah (BKB) dengan cara sebagai berikut:

$$
\begin{aligned}
& B K A=\bar{X}+2 \delta x . \\
& B K B=\bar{X}-2 \delta x .
\end{aligned}
$$

Memindahkan data yang telah diperoleh kedalam bentuk grafik dengan batas-batas kontrol yang telah ditetapkan. Apabila data yang diperoleh tersebut terdapat data yang berada diluar batas kontrol. Maka data tersebut harus dihilangkan dan dilakukan perhitungan kembali seperti semula. Karena data yang berada diluar batas kontrol menyebabkan data tidak seragam.

Beban kerja yang baik, lebih disukai mendekati $100 \%$ atau dalam kondisi normal. Berarti $100 \%$ beban kerja bahwa selama 8 jam kerja, pekerja dapat bekerja terus menerus dalam kondisi normal(Sari et al., 2019).

Pada langkah ini, waktu kerja efektif dihitung. Tujuan perhitungan adalah untuk mendapatkan informasi tentang
Waktu kerja pekerja nyata yang menunjukkan bahwa proporsi waktu kerja sangat rendah berarti bahwa sebagian besar waktu pekerja melakukan kegiatan yang tidak efektif seperti menunggu pekerjaan. Perusahaan dapat mengurangi waktu yang tidak efektif ini dengan penjadwalan yang tepat, perusahaan dapat mengurangi biaya operasi(Dewi \& Septiana, 2015).

Waktu normal ialah waktu yang telah mempertimbangkan faktor-faktor penyesuaian, yaitu waktu siklus dikalikan dengan faktor penyesuaian,dengan faktor penyesuain tersebut maka di dapat waktu normal dari masing masing stasiun kerja(Hermawan et al., 2019)

Perhitungan Waktu Normal

$\mathrm{Wn}=\mathrm{Ws} \times \mathrm{p}$

Dengan $\mathrm{p}$ adalah faktor penyesuaian. Faktor ini diperlukan jika pengukur berpendapat bahwa operator bekerja dengan tidak wajar, sehingga perhitungan waktu perlu disesuaikan atau dinormalkan dulu untuk mendapat waktu siklus rata - rata yang wajar. Jika pekerja bekerja dengan wajar, maka faktor penyesuaiannya $\mathrm{p}$ sama dengan 1 , artinya waktu siklus rata - rata sudah normal.

Perhitungan Waktu Baku

$\mathrm{Wb}=\mathrm{Wn} \times(1+\mathrm{A})$

Dengan $\mathrm{A}=$ kelonggaran

Allowence atau kelonggaran yang diberikan kepada pekerja untuk menyelesaikan pekerjaannya di samping waktu normal. Kelonggaran ini diberikan untuk hal - hal seperti:

(a) Kelonggaran untuk pribadi.

(b) Kelonggaran untuk menghilangkan rasa lelah.

(c) Kelonggaran untuk hal - hal yang tak terhindar 
Beban kerja sangat berpengaruh dalam produktivitas kinerja karyawan karena lingkungan dan kapasitas kerja disesuaikan dengan produktivitas. Jika beban yang diterima terlalu berat, produktivitas karyawan akan menurun, sebaliknya jika beban kerja seimbang maka produktivitas karyawan akan meningkat (Hanjani \& Singgih, 2019).

Penyeimbangan Beban Kerja Operator Penyeimbangan lini produksi ini dilakukan dengan beberapa tahapan yaitu:

a. Melakukan perhitungan beban kerja operator pada keadaan awal dengan metode workload analysis. Yang terdiri dari beberapa tahapan, yaitu :

i) Melakukan verifikasi mengenai job description untuk setiap operator di bagian case assy UP.

ii) Melakukan perhitungan beban kerja.

b. Setelah mengetahui kondisi keadaan awal beban kerja tiap operator, maka akan dilakukan penyeimbangan beban kerja dengan metode workload analysis.

\section{Hasil dan Pembahasan}

Data rencana produksi dan MPS diperlukan dalam pembuatan mapping karena merupakan salah satu informasi penting yang harus ada dalam suatu pemetaan proses. Data rencana produksi dan actual output harus tergambar dalam sebuah current state, sehingga dapat dilakukan analisis dengan membandingkan nilai keduanya untuk mengetahui produktivitas Case Assy UP. Adapun data rencana produksi Case Assy UP PT Yamaha Indonesia untuk September 2015 adalah sbb. :

Berdasarkan tabel 2 rencana produksi bulan September, rencana unit/day didapat dari rencana unit/month dibagi dengan hari kerja pada bulan September yang berjumlah 21 hari.

$$
\begin{aligned}
\text { Konversi B1 } & =\text { Unit/day }(92 \times \text { Total/day }) \\
& =46 \times(92 \times 118) \\
& =36
\end{aligned}
$$

Tabel 2. Rencana Produksi September 2015

Schedule September

\begin{tabular}{lccc}
\cline { 2 - 4 } Model & Unit/month & Unit/day & $\begin{array}{c}\text { Konversi } \\
\text { ke 92 } \\
\text { unit }\end{array}$ \\
\hline B1 & 973 & 46 & 36 \\
B2 & 596 & 28 & 22 \\
B3 & 391 & 19 & 14 \\
b113/b121 & 140 & 7 & 5 \\
M2/M3/M5 & 51 & 2 & 2 \\
P22 & 21 & 1 & 1 \\
P116 & 37 & 2 & 1 \\
U1J & 278 & 13 & 10 \\
Total & 2487 & 118 & 92 \\
\hline
\end{tabular}


Tabel 3. Hasil Perhitungan Beban Kerja Sebelum Perbaikan

\begin{tabular}{lcccccc}
\hline \multicolumn{1}{c}{ Proses } & $\begin{array}{c}\text { Waktu } \\
\text { Siklus }\end{array}$ & $\begin{array}{c}\text { WS } \\
\text { Proporsional }\end{array}$ & $\begin{array}{c}\text { Waktu } \\
\text { Normal }\end{array}$ & $\begin{array}{c}\text { Waktu } \\
\text { Baku }\end{array}$ & $\begin{array}{c}\text { Total } \\
\text { Waktu } \\
\text { Baku }\end{array}$ & $\begin{array}{c}\text { Beban } \\
\text { Kerja }\end{array}$ \\
\hline Belah Key Blok & 0.38 & 0.13 & 0.14 & 0.16 & 5.65 & $1.23 \%$ \\
Pasang Key Blok & 3.61 & 1.20 & 1.30 & 1.51 & 54.33 & $11.81 \%$ \\
Pasang H Striep & 2.48 & 0.62 & 0.67 & 0.78 & 27.99 & $6.08 \%$ \\
Pasang Cab Set & 3.45 & 0.86 & 0.93 & 1.08 & 38.94 & $8.47 \%$ \\
Belah Key Blok & 0.38 & 0.13 & 0.14 & 0.16 & 3.46 & $0.75 \%$ \\
Pasang Key Blok & 6.09 & 2.03 & 2.19 & 2.54 & 55.92 & $12.16 \%$ \\
Pasang H Striep & 3.28 & 0.82 & 0.89 & 1.03 & 22.62 & $4.92 \%$ \\
Pasang Cab Set & 4.13 & 1.03 & 1.12 & 1.29 & 28.48 & $6.19 \%$ \\
Belah Key Blok & 0.38 & 0.38 & 0.41 & 0.47 & 2.36 & $0.51 \%$ \\
Pasang Key Blok & 6.91 & 6.91 & 7.46 & 8.66 & 43.29 & $9.41 \%$ \\
Pasang H Striep & 2.55 & 2.55 & 2.75 & 3.19 & 15.97 & $3.47 \%$ \\
Pasang Cab Set & 7.37 & 7.37 & 7.96 & 9.24 & 46.18 & $10.04 \%$ \\
Belah Key Blok & 0.38 & 0.38 & 0.41 & 0.47 & 0.94 & $0.20 \%$ \\
Pasang Key Blok & 6.63 & 6.63 & 7.16 & 8.30 & 16.60 & $3.61 \%$ \\
Pasang H Striep & 1.67 & 1.67 & 1.80 & 2.09 & 4.18 & $0.91 \%$ \\
Pasang Cab Set & 3.49 & 3.49 & 3.76 & 4.37 & 8.73 & $1.90 \%$ \\
Belah Key Blok & 0.38 & 0.38 & 0.41 & 0.47 & 0.47 & $0.10 \%$ \\
Pasang Key Blok & 5.37 & 5.37 & 5.80 & 6.73 & 6.73 & $1.46 \%$ \\
Pasang H Striep & 3.97 & 3.97 & 4.28 & 4.97 & 4.97 & $1.08 \%$ \\
Pasang Cab Set & 4.66 & 4.66 & 5.03 & 5.84 & 5.84 & $1.27 \%$ \\
Pasang Back Post Felt & 2.45 & 2.45 & 2.65 & 3.07 & 15.35 & $3.34 \%$ \\
& & 53.01 & 57.25 & 66.41 & 408.99 & $88.91 \%$ \\
\hline
\end{tabular}


Tabel 4. Kategori Beban Kerja Per Operator

\begin{tabular}{cccc}
\hline No. & Operator & Beban Kerja & Kategori \\
& & & \\
\hline 1 & Operator 1 & $88.91 \%$ & Underload \\
2 & Operator 2 & $89.76 \%$ & Underload \\
3 & Operator 3 & $92.25 \%$ & Underload \\
4 & Operator 4 & $86.86 \%$ & Underload \\
5 & Operator 5 & $69.58 \%$ & Underload \\
6 & Operator 6 & $72.85 \%$ & Underload \\
7 & Operator 7 & $73.00 \%$ & Underload \\
8 & Operator 8 & $67.93 \%$ & Underload \\
& Rata-rata & $\mathbf{8 0 . 1 4 \%}$ & \\
\hline
\end{tabular}

Setelah dihitung beban kerja operator Case Assy UP ternyata hasil nya beban kerja operator belum seimbang dan masih bisa diubah agar hasil menjadi lebih seimbang.

Contoh perhitungan beban kerja pada Operator 1 untuk proses belah key block model B1 :

1. WSP

$=$ Waktu Siklus x Persentase Pekerjaan Operator

$=0.38 \times 70 \%$

$=0.26$ menit

2. Waktu Normal

$=$ WS Proporsional $\mathrm{x}(1+$ Rating Factor $)$

$=0.26 \times(1+0.08)$

$=0.28$ menit

3. Waktu Baku

$=$ Waktu Normal x $(1+$ Allowance $)$

$=0.28 \times(1+16 \%)$

$=0.33$ menit

4. TWB

$=$ Waktu Baku x Plan prod.

$=0.33 \times 36$

$=11.87$ menit
5. Beban Kerja

$$
\begin{aligned}
& =\frac{\text { Total Waktu Baku }}{\text { Total waktu kerja }} \times 100 \% \\
& =\frac{11.87}{460} \times 100 \% \\
& =2.58 \%
\end{aligned}
$$

Permasalahan yang ada di bagian Case Assy $U P$ adalah beban kerja yang terlihat belum seimbang. Berikut ini adalah tabel total cycle time untuk mengetahui jumlah operator dan

\begin{tabular}{|c|c|c|c|}
\hline Model & $\begin{array}{c}\text { Plan } \\
\text { (Unit) }\end{array}$ & $\begin{array}{l}\text { Cycle } \\
\text { Time }\end{array}$ & $\begin{array}{l}\text { Total } \\
\text { Cycle } \\
\text { Time }\end{array}$ \\
\hline B1 & 36 & 26.02 & 936.48 \\
\hline B2 & 22 & 31.00 & 683.44 \\
\hline B3 & 14 & 34.22 & 494.97 \\
\hline B113/B121 & 5 & 37.60 & 194.73 \\
\hline P116 & 2 & 29.38 & 55.42 \\
\hline P22 & 1 & 29.23 & 22.70 \\
\hline M2/M3/M5 & 1 & 28.73 & 39.32 \\
\hline U1J/P121 & 10 & 33.81 & 347.72 \\
\hline \multicolumn{3}{|c|}{ Total } & 2774.8 \\
\hline
\end{tabular}
angka produktivitas yang ideal :

Tabel 5. Total Cycle Time 
Dari tabel diatas didapatkan perhitungan : Total

Cycle Time $=$ Plan (unit) $x$ Cycle Time

Operator ideal

$$
\begin{aligned}
& =\frac{\text { Total Time }}{\text { Beban kerja (\$6) }} \\
& \text { Menit kerja } \\
& =\frac{2774,8}{\frac{9536}{460}} \\
& =6,3 \text { orang }
\end{aligned}
$$

\begin{tabular}{|c|c|c|c|c|c|c|}
\hline Proses & $\begin{array}{l}\text { Waktu } \\
\text { Siklus }\end{array}$ & $\begin{array}{l}\text { Waktu Siklus } \\
\text { Proporsional }\end{array}$ & $\begin{array}{c}\text { Waktu } \\
\text { Normal }\end{array}$ & $\begin{array}{c}\text { Waktu } \\
\text { Baku }\end{array}$ & $\begin{array}{c}\text { Total } \\
\text { Waktu } \\
\text { Baku }\end{array}$ & $\begin{array}{l}\text { Beban } \\
\text { Kerja }\end{array}$ \\
\hline Belah Key Blok & 0.38 & 0.26 & 0.28 & 0.33 & 11.87 & $2.58 \%$ \\
\hline Pasang Key Blok & 3.61 & 1.81 & 1.95 & 2.26 & 81.49 & $17.72 \%$ \\
\hline Pasang Cab Set & 2.48 & 0.35 & 0.37 & 0.43 & 15.58 & $3.39 \%$ \\
\hline Pasang H Striep & 3.45 & 0.25 & 0.27 & 0.31 & 11.19 & $2.43 \%$ \\
\hline Belah Key Blok & 0.38 & 0.19 & 0.20 & 0.24 & 5.18 & $1.13 \%$ \\
\hline Pasang Key Blok & 6.09 & 3.04 & 3.29 & 3.81 & 83.88 & $18.23 \%$ \\
\hline Pasang H Striep & 3.28 & 0.33 & 0.35 & 0.41 & 9.05 & $1.97 \%$ \\
\hline Pasang Cab Set & 4.13 & 1.03 & 1.12 & 1.29 & 28.48 & $6.19 \%$ \\
\hline Belah Key Blok & 0.38 & 0.38 & 0.41 & 0.47 & 2.36 & $0.51 \%$ \\
\hline Pasang Key Blok & 6.91 & 6.91 & 7.46 & 8.66 & 43.29 & $9.41 \%$ \\
\hline Pasang H Striep & 2.55 & 2.55 & 2.75 & 3.19 & 15.97 & $3.47 \%$ \\
\hline Pasang Cab Set & 7.37 & 2.46 & 2.65 & 3.08 & 15.39 & $3.35 \%$ \\
\hline Belah Key Blok & 0.38 & 0.38 & 0.41 & 0.47 & 0.94 & $0.20 \%$ \\
\hline Pasang Key Blok & 6.63 & 6.63 & 7.16 & 8.30 & 16.60 & $3.61 \%$ \\
\hline Pasang H Striep & 1.67 & 1.67 & 1.80 & 2.09 & 4.18 & $0.91 \%$ \\
\hline Pasang Cab Set & 3.49 & 1.16 & 1.25 & 1.46 & 2.91 & $0.63 \%$ \\
\hline Belah Key Blok & 0.38 & 0.38 & 0.41 & 0.47 & 0.47 & $0.10 \%$ \\
\hline Pasang Key Blok & 5.37 & 5.37 & 5.80 & 6.73 & 6.73 & $1.46 \%$ \\
\hline Pasang H Striep & 3.97 & 3.97 & 4.28 & 4.97 & 4.97 & $1.08 \%$ \\
\hline Pasang Cab Set & 4.66 & 1.55 & 1.68 & 1.95 & 1.95 & $0.42 \%$ \\
\hline Pasang Back Post Felt & 2.45 & 2.45 & 2.65 & 3.07 & 15.35 & $3.34 \%$ \\
\hline Belah Key Blok & 0.38 & 0.19 & 0.20 & 0.24 & 3.30 & $0.72 \%$ \\
\hline Pasang Key Blok & 5.37 & 2.60 & 2.80 & 3.25 & 45.54 & $9.90 \%$ \\
\hline Pasang H Striep & 3.97 & 0.77 & 0.83 & 0.96 & 13.45 & $2.92 \%$ \\
\hline Pasang Cab Set & 4.66 & 1.03 & 1.12 & 1.29 & 18.12 & $3.94 \%$ \\
\hline Total & & 47.68 & 51.50 & 59.74 & 458.25 & $99.62 \%$ \\
\hline
\end{tabular}

Sedangkan produktivitas ideal adalah :

Produktivitas ideal

$$
\begin{aligned}
& =\frac{\text { Total Plan }}{\frac{\text { umlah Operator Ideal }}{\text { Jam Kerja }}} \\
& =\frac{92}{8.8} \\
& =1.81 \text { unit/orang/jam }
\end{aligned}
$$

Tabel 6 Hasil Perhitungan Beban Kerja Setelah Perbaikan 
Tabel 7. Kategori Beban Kerja Per Operator

\begin{tabular}{cccc}
\hline No. & Operator & Beban Kerja & Kategori \\
\hline 1 & Operator 1 & $99.62 \%$ & Underload \\
2 & Operator 2 & $99.97 \%$ & Underload \\
3 & Operator 3 & $99.03 \%$ & Underload \\
4 & Operator 6 & $97.28 \%$ & Underload \\
5 & Operator 7 & $97.28 \%$ & Underload \\
6 & Operator 8 & $96.28 \%$ & Underload \\
& Rata-rata & $\mathbf{9 8 . 2 4 \%}$ & \\
\hline
\end{tabular}

Setelah beban kerja operator Case Assy UP diperbaiki maka dapat dilihat hasil nya seperti pada tabel dan grafik diatas. Dimana terjadi pengurangan operator yang sebelumnya 8 operator menjadi 6 operator. Rata-rata beban kerja operator juga terjadipeningkatan dari sebelumnya $82,21 \%$ menjadi $97.66 \%$.

Melalui tercapainya kesesuaian penetapan jumlah tenaga kerja, maka suatu perusahaan dapat meningkatkan efektivitas kerja karena cost yang dikeluarkan karyawan dalam bentuk tenaga sebanding dengan output yang dihasilkan (Dannies et al., 2015).

\subsection{Perhitungan Produktivitas Case Assy UP}

Perhitungan produktivitas adalah mengetahui angka produktivitas, dimana produktivitas sebelum perbaikan beban kerja pada bulan September, Oktober, dan November sedangkan produktivitas setelah perbaikan terjadi pada bulan Desember, dan Januari.

Dari tabel diatas didapatkan perhitungan produktivitas pada tanggal 1 dan seterusnya pada bulan September sebagai berikut :

$$
\begin{aligned}
\text { Produktivitas } & =\frac{\text { Jumlah Output }}{\frac{\text { Jumlah operator aktual/hari }}{\text { Waktu Kerja+OT }}} \\
& =\frac{\frac{70}{8}}{10.1} \\
& =0,8 \text { unit/orang/hari }
\end{aligned}
$$

Tabel 8. Data Produktivitas Case Assy UP Bulan Oktober 2014

\begin{tabular}{lc}
\hline & Oktober \\
& $\mathbf{2 0 1 4}$ \\
& Tanggal \\
& $\mathbf{1}$ \\
\hline Output & 70 \\
Waktu Kerja (jam) & 8 \\
Man Power & 8 \\
Absent (menit) & 0 \\
Trans out (menit) & 0 \\
Trans in (menit) & 144 \\
Operator Aktual & 8 \\
Operator Overtime & 7 \\
Waktu Overtime (jam) & 2.1 \\
Produktivitas & 0.8 \\
Target Produktivitas & 1.81 \\
\hline
\end{tabular}


Berikut ini adalah resume produktivitas dari bulan September sampai dengan bulan Januari.

Tabel 9. Resume Produktivitas

\begin{tabular}{|c|c|c|c|c|}
\hline $\begin{array}{c}\text { Produc } \\
\text { tivity } \\
\text { Case } \\
\text { Assy }\end{array}$ & $\begin{array}{c}\text { Productivity } \\
\text { (unit/orang/jam) }\end{array}$ & $\begin{array}{c}\text { Man } \\
\text { Power }\end{array}$ & $\begin{array}{c}\text { AVG } \\
\text { Operat } \\
\text { or }\end{array}$ & $\begin{array}{l}\text { Output } \\
8 \text { hour }\end{array}$ \\
\hline 14-Oct & 1.22 & 8 & 8 & 81 \\
\hline $\begin{array}{l}14- \\
\text { Nov }\end{array}$ & 1.25 & 8 & 9 & 88 \\
\hline 14-Dec & 1.42 & 7 & 7 & 83 \\
\hline $15-J a n$ & 1.42 & 7 & 7 & 81 \\
\hline $15-\mathrm{Feb}$ & 1.38 & 7 & 7 & 81 \\
\hline $\begin{array}{l}\text { 15- } \\
\text { Mar }\end{array}$ & 1.33 & 7 & 8 & 86 \\
\hline 15-Apr & 1.08 & 7 & 6 & 55 \\
\hline $\begin{array}{l}\text { 15- } \\
\text { May }\end{array}$ & 1.19 & 7 & 6 & 61 \\
\hline 15-Jun & 1.32 & 7 & 7 & 69 \\
\hline 15-Jul & 1.41 & 7 & 7 & 81 \\
\hline $\begin{array}{l}15- \\
\text { Aug }\end{array}$ & 1.59 & 7 & 7 & 86 \\
\hline 15-Sep & 1.56 & 7 & 7 & 88 \\
\hline $15-\mathrm{Oct}$ & 1.59 & 7 & 7 & 87 \\
\hline $\begin{array}{l}15- \\
\text { Nov }\end{array}$ & 1.59 & 7 & 7 & 86 \\
\hline 15-Dec & 1.76 & 7 & 6 & 87 \\
\hline 16-Jan & 1.92 & 7 & 6 & 85 \\
\hline 16-Feb & 1.82 & 7 & 6 & 93 \\
\hline
\end{tabular}

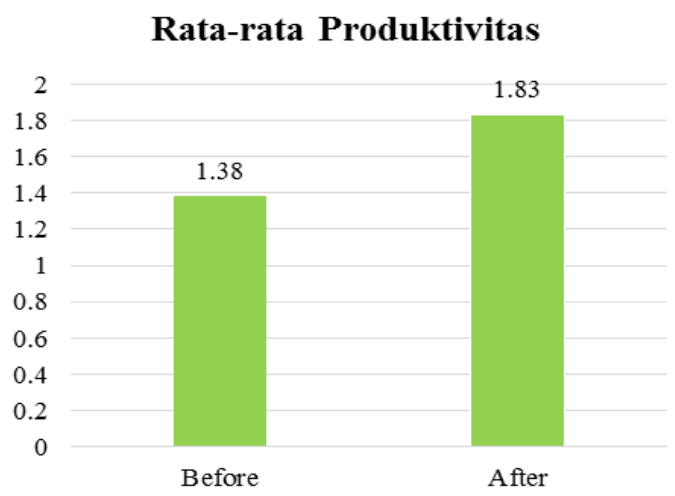

Gambar 1. Perbandingan Produktivitas
Perbandingan produktivitas pada tabel diatas adalah perbandingan produktivitas before dan after. Rata-rata produktivitas didapat dari rata-rata produktivitas pada bulan Oktober 2014 sampai November 2015, sedangkan rata-rata produktivitas didapat dari rata-rata produktivitas pada bulan Desember 2015 sampai Februari 2016.

\subsection{Perhitungan Cost Saving}

Perhitungan cost saving disini akan membandingkan penghematan biaya sebelum dan sesudah perbaikan yang termasuk waktu kerja per hari dan jumlah hari kerja dalam satu bulan.

Cost Saving = (Operator sebelum - operator sesudah) x Wage Rate x Waktu kerja (menit/hari) x Jumlah hari kerja (sebulan)

$$
\begin{aligned}
& =(8-6) \times 0,0777 \times 460 \times 20 \\
& =\$ .1429 .52
\end{aligned}
$$

\section{Kesimpulan}

Berdasarkan hasil pengumpulan dan pengolahan data serta analisa yang telah dilakukan pada bab-bab sebelumnya maka dapat diambil kesimpulan untuk menjawab rumusan masalah pada penelitian ini yaitu sebagai berikut.

Dengan menggunakan metode workload analysis rata-rata hasil produktivitas meningkat sebesar 33\% dibandingkan dengan rata-rata produktivitas awal. Semakin sedikit jumlah operator maka semakin tinggi beban kerjanya dan dengan melakukan pemerataan beban kerja didapatkan jumlah operator dan beban kerja yang optimal. Beban kerja operator menjadi lebih seimbang karena beban kerja awal dengan jumlah 8 operator didapatkan beban kerja tertinggi $92,25 \%$ dan beban kerja terendah sebesar $67,93 \%$, sedangkan setelah perbaikan dengan jumlah 8 operator didapatkan beban 
kerja tertinggi 99,97\% dan beban kerja terendah sebesar 96,28\%. Dengan mengurangi jumlah operator sebanyak 2 orang maka beban kerja lebih ideal dan mengurangi biaya tenaga kerja.

\section{Daftar Pustaka}

Adawiyah, W. (2013). Analisis Beban Kerja Sumber Daya Manusia dalam Aktivitas Produksi Komoditi Sayuran Selada ( Studi Kasus: CV Spirit Wira Utama ). Managemen Dan Organisasi, IV(2), 128143.

Anggraeni, L. E., \& Prabowo, R. (2015). Analisis Beban Kerja Untuk Menentukan Jumlah Karyawan Optimal ( Studi Kasus : Pt . Sanjayatama Lestari Sirabaya ). Jurnal Teknik Industri, 225-232.

Ariani, F., Siregar, K., \& Tugiman. (2019). Determination of Total Labor Plant 1 using Workload Analysis (WLA) Method in Compound Fertilizer's Industry. IOP Conference Series: Materials Science and Engineering,648(1).

https://doi.org/10.1088/1757-

899X/648/1/012015

Balina, S., Baumgarte, D., \& Salna, E. (2015). The Model for Balancing Learning Workload. Procedia Computer Science, 77,113-118.

https://doi.org/10.1016/j.procs.2015.12.36 7

Dannies, N., Halim, Verina , Haryanto, H., Jurnal, Universitas, M., \& Vol, S. (2015). Analisis Beban Kerja PT. X Nina Dannies, Verina Halim \& Heru Haryanto. 4(1), 112.

Dewi, D. S., \& Septiana, T. (2015). Workforce Scheduling Considering Physical and Mental Workload: A Case Study of Domestic Freight Forwarding. Procedia Manufacturing, 4(Iess), 445-453. https://doi.org/10.1016/j.promfg.2015.11.0 61

Diana, B. A., \& Harta, R. (2017). Analisis Beban Kerja Pegawai Pada Kantor UPBJJ-
Universitas Terbuka Bandung. Jurnal Manajemen Pelayanan Publik, 1(1), 1. https://doi.org/10.24198/jmpp.v1i1.13555

Hanjani, A. R., \& Singgih, M. L. (2019). Workload Analysis at Biro Human Capital to Increase Productivity. IPTEK Journal of Proceedings Series, O(5), 404. https://doi.org/10.12962/j23546026.y2019i 5.6377

Hermawan, R., Banjarsari, D. I., \& Ciamis, K. (2019). Teknik Industri Fakultas Teknik Universitas Galuh Ciamis 46215. 06(01), 91-114.

Hidayat, A., \& Partiwi, S. G. (2018). Perhitungan jumlah tenaga kerja yang optimal pada cleaning pabrik personal wash PT. Unilever Indonesia. Http:Www.Digilib.Its.Ac.Id/Public/ItsPaper-34509-2509100101-Paper.Pdf., 15.

Inegbedion, H., Inegbedion, E., Peter, A., \& Harry, L. (2020). Perception of workload balance and employee job satisfaction in work organisations. Heliyon, 6(1), e03160. https://doi.org/10.1016/j.heliyon.2020.e03 160

Lestari, A. P. (2014). Pendaftaran Pasien Rawat Jalan Berdasarkan Rumus Fulltime Equivalent ( Fte ) Di Rsud Kota Surakarta Tahun. 1-12.

Mishan, N. N., \& Tap, M. M. (2015). Increasing Line Efficiency By Using Timestudy and Line Balancing in a Food Manufacturing Company. Jurnal Mekanikal, 38, 32-43.

Rahmat Hermawan, N., \& Banjarsari. (2019). Teknik Industri Fakultas Teknik Universitas Galuh Ciamis 46215. 06(01), 91-114.

Ridha, I. R., Bakar, A., \& Nugraha, C. (2013). Usulan Kebutuhan Jumlah Tenaga Kerja di Bagian Water Based PT . X Berdasarkan Analisis Beban Kerja *. 1(2).

Rizky Ramadhan, M., Yuniati, Y., \& Arijanto, S. (2014). Analisis Beban Kerja Dan 
Pengukuran Gap Kompetensi Teknisi Laboratorium Umum. Jurnal Online Institut Teknologi Nasional Juli, 02(03), 2338-5081.

Sari, R. M., Tarigan, U., Rizkya, I., \& Elvira. (2019). Workload of Workforce in Fertilizing Industry: An Analysis. IOP Conference Series: Materials Science and Engineering,648(1). https://doi.org/10.1088/1757899X/648/1/012019 